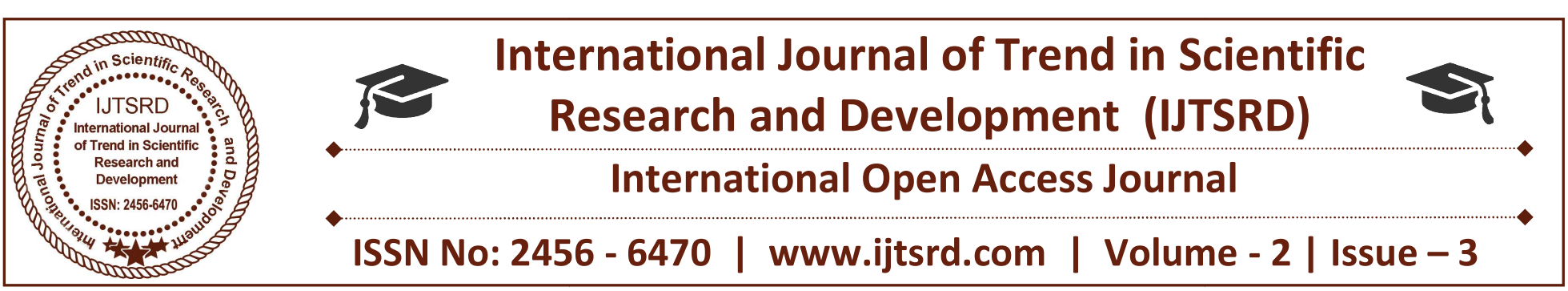

\title{
Critical thinking skills and its development strategies
}

\author{
Mr. Govind Singh \\ Research Scholar (Edu.), Jaipur National University, Jaipur, Rajasthan, India
}

\begin{abstract}
Have you ever thought that critical thinking can help you to be objective? It actually can. To appreciate this, bear in mind the fact that whenever you are engaged in critical thinking, you are not going to respond to something instantaneously. Instead, when you hear something, whether it is a question or a statement, you are going to ensure you heard it right. Then you will proceed to assess what it could actually mean in the context it was said. Only then will you be set to make a decision depending upon whether it is something you can believe or relate to or not. What you will eventually see is that after evaluating all the different sections of what you have listened to, and you have had opportunity to consolidate the different meanings, the conclusion you come to is normally one that is reasonable and objective.
\end{abstract}

Keywords: Critical, Judgments, Cognitive, Research, Logical, Incisive, Significant, Emotions, Omega-3.

\section{Concept of critical thinking}

Critical thinking means different things to different people. In a university context, the term is generally used to describe the ability to analyze a problem and present a solution to it. The word 'critical' implies that your intelligence is applied to a specific issue or problem and that a weighing up of options is an integral part of the process. Critical thinking is the ability to think clearly and rationally about what to do or what to believe. It includes the ability to engage in reflective and independent thinking. Someone with critical thinking skills is able to do the following:

- understand the logical connections between ideas

- identify, construct and evaluate arguments
- detect inconsistencies and common mistakes in reasoning

- $\quad$ solve problems systematically

- identify the relevance and importance of ideas

- reflect on the justification of one's own beliefs and values

Disciplined, self-directed thinking which exemplifies the perfection of thinking appropriate to a particular mode or domain of thinking (Paul, 1989, p. 214)

\section{Critical thinking is...}

- Incisive, seeing through complexity and obscurity

- n Logical, deploying evidence towards a clear position

- Deep, involving higher level skills of analysis, synthesis and judgment

\section{Critical thinking is not...}

- Disorganized, being a haphazard collection of ideas

- Prejudiced, ignoring evidence on one side of an issue

- Unsubstantiated, failing to take account of evidence

\section{The elements of critical thinking}

Cognitive strategies - micro-skills: comparing and contrasting ideals with actual practice

$>$ Thinking precisely about thinking: using critical vocabulary Noting significant similarities and difference

Examining or evaluating assumptions 
$>$ Distinguishing relevant from irrelevant facts

$>$ Making plausible inferences, predictions, or interpretations

Giving reasons and evaluating evidence and alleged facts recognizing contradictions

$>$ Exploring implications and consequences. Cognitive strategies-macro-skills: refining generalizations and avoiding oversimplifications

> Comparing analogous situations: transferring insights to new contexts

> Developing one's perspective: creating or exploring beliefs, arguments, or theories

> Clarifying issues, conclusions, or beliefs

$>$ Developing criteria for evaluation: clarifying values and standards

$>$ Evaluating the credibility of sources of information

$>$ Questioning deeply: raising and pursuing root or significant questions

> Analyzing or evaluating Int arguments, interpretations, beliefs, or theories

Generating or assessing solutions

$>$ Analyzing or evaluating actions or policies

$>$ Reading critically: clarifying or critiquing texts

$>$ Listening critically: the art of silent dialogue

$>$ Making interdisciplinary connections

> Practicing Socratic discussion: clarifying and questioning beliefs, theories, or perspectives

$>$ Reasoning dialogically: comparing perspectives, interpretations, or theories.

> Reasoning dialectically: evaluating perspectives, interpretations, or theories. (Richard W. Paul, Developing Minds, revised edition, vol. 1, 1991, p. 78. (C) Richard W. Paul)

\section{Who is a good critical thinker?}

$>$ One who is guided by reason

$>$ One who is not guided just by emotions

$>$ One who considers all the evidence at hand and follows the route that the evidence points towards

One who is in search for the best explanation

$>$ One who is free from motives or biases
$>$ One who is aware of her own prejudices

$>$ One who is fair and open minded

> One who Raises vital questions and problems, formulating them clearly and precisely;

$>$ One who Gathers and assesses relevant information, using abstract ideas to interpret it effectively

$>$ One who Comes to well-reasoned conclusions and solutions, testing them against relevant criteria and standards

\section{Strategies to improve critical thinking}

Critical thinking is all about solving problems, using logical thinking as a guide. When your logical thinking happens to be flawed, then you will find that solving problems can be a challenge, and that the decisions you make will not be good. Now that you know how to develop your critical thinking skills, you need some guidance on improving these skills so that they can be perfected over time. The end result is that instead of spending too much time thinking hard about a problem, you will be able to think better.

Making a conscious effort to focus on the challenge Much as everyone wants to solve problems, not everyone is willing to devout sufficient time to focus directly on the problem at hand. Yet when you do, you are able to address the issue in its correct perspective and evaluate it within the prevailing circumstances. It is unlikely you will ever have a panacea to all your problems even when those challenges look similar - there are always factors like timing, environment and others that call for each problem to be addressed in isolation.

Learn to ask critical questions It is important to learn how to tailor your questions so that you can provoke your source into responding in a way that is relevant and helpful to your situation. And even when it comes to designing questions to help you in your research, you'll need to frame them in a way that leads you to relevant sources, and fast.

Learn and practice to support your ideas with verifiable evidence as well as logical thinking

Get used to analyzing an issue before coming up with deductions. At the same time you need to be serious in your reasoning and evaluation. 
$>$ Get into the habit of interpreting matters in depth; avoiding the temptation to take information at face value.

$>$ Learn to synthesize the many ideas that are available to you

$>$ Practice handling complex questions by breaking them down first Practice making decisions only after evaluating them properly

Learn to generate options and evaluating them before you can pick any of them as your choice

$>$ Practice being detail oriented so that you can derive meanings that are as precise as possible.

Learn to apply high level thinking to help you analyze and solve real life challenges

Make critical thinking a daily habit and not something you do once in a while

$>$ Practice categorizing your ideas according to the value you attach to each of them

$>$ Be reflective in your thinking

Learn to engage only in undertakings that lead to problem solving

Keep learning

> Practice being open to new ideas; and be ready to see things from different viewpoints

$>$ Always seek improved solutions

$>$ Be open to alternative solutions

$>$ Practice having an open mind to ideas, techniques as well as solutions Learn to respect other people's ideas and points of view

$>$ Practice checking the veracity of information, be it the one picked from books or the Internet; form observation from other people and other sources.

$>$ Learn to evaluate possible repercussions before you make any move towards handling a problem

Learn to collaborate with other people when it comes to problem solving

Keep observing fundamental intellectual standards when handling issues of all kinds

\section{Strategies to Improve brain power}

Exercises to keep your brain in tip top condition for good critical thinker

\section{Make Exercise Fun}

Research shows that those who get an adequate amount of physical exercise are also exercising their brains.

\section{Exercise the brain for a good critical thinking}

It's not only physical exercise that has your brain cells growing. You can build up different areas of the brain by putting those areas to work. Finding ways to use different parts of your brain that are simple could help maintain the dendrites and nerve cells in your brain You should go out of your way to experience new smells, tastes, and physical feelings. Use your non-dominant hand for some activities, and find new ways to drive to work, or travel to new places. Try to create artwork or read a challenging novel. You want to force yourself to do something out of your mental rut.

\section{$>$ Ask Why}

Your brain is wired to be curious. When you are grown up and matured, you may stifle or deny your natural curiosity, but that's not healthy. Let yourself wonder why! Wonder about why things are happening in the world, or why you are where you are in life. Ask someone who knows about the why questions you are asking. The best way to exercise your brain is to exercise your curiosity by asking why and making it a habit.

\section{$>$ Laugh}

Laughter is good for your health because it releases endorphins in the brain and positivity chemicals that affect our system. We don't need a scientist to tell us that laughing feels great. Laughing relieves stress and helps break old patterns, too. Laugh more and harder, and you'll quick-charge your brain's battery.

\section{Eat Omega-3}

Most of you know that by eating fish you will get more Omega-3, but do you know why it's good for your brain and not just your heart? Omega-3 helps your heart pump more oxygen to your brain, and recently, has been shown to help your brain function 
better by improving the function of the membranes that are around your brain cells.

\section{Remember}

When you're feeling nostalgic, get out an old yearbook or some photo albums and take a walk down memory lane. Spending time with your memories will help your brain get exercise! Let your mind reflect on the positive emotions and connections from those memories, and I guarantee that you will feel better about the current challenges you're facing.

\section{Cut Out Fat}

Saturated fats found in meats and dairy products have actually shown to cause a slow-down of the brain's functions. A study done at the University of Toronto proved this by taking rats and putting them on a fortypercent fat diet. They lost abilities in the areas of memory, mental function, rule learning, and spatial awareness. When their diet was higher in saturated fats, their problems became even worse.

\section{Puzzles}

Crosswords, jigsaws, logic, whatever your forte is when it comes to puzzles, keep doing them! Doing a puzzle is going to activate your mind and keep it in working condition. So, do the puzzle for fun, but know that you're exercising your brain at the same time.

\section{Mozart}

Effect Around ten years ago, Frances Rauscher and colleagues made history when they figured out that listening to Mozart could improve a person's spatial and mathematical reasoning.

\section{Improve Existing Skills}

Repetitive information is okay as long as you are attempting to expand your knowledge. Activities like reading, gardening, playing bridge, sewing, crossword puzzles, and painting are all viable ways to build your brain, but you have to push to find new ways to do these activities. Try a different type of gardening or try reading something that's not of your usual genre. Pushing your brain to its max is actually healthy for the brain. Strive to do that more often!

\section{$>$ Avoid Alcohol}

Alcohol killing brain cells is actually The common practice of binge drinking is the most dangerous kind because it not only kills a lot of brain cells initially, it keeps the brain from creating new ones around thirty days after just one incident of binge drinking. So while alcohol is okay in moderation and might even be beneficial to your health, binge drinking and alcoholism should be avoided or treated

\section{$>$ Play}

Studies have shown that people who take the time to play cards, video games, board games, tug of war, or any other activities for pleasure is good for their soul and their brain! It allows the brain to think strategically and keep working, but in a stress-free environment.

\section{Concentrate}

When you are concentrating, you are increasing your brainpower. You should learn to know when you're being distracted so that you can adjust your focus. Often, one of the thieves of concentration is just below your consciousness.

\section{Make Love}

Regular physical contact, especially intimate contact, is especially important for women's concentration and emotion wellbeing. Contact with a partner on a weekly basis leads to regular, more fertile menstrual cycles, as well as increase estrogen levels. It will even delay aging and make women have shorter menstrual cycles. Decreased estrogen levels in women are associated with a decrease in the brain activity and poor memory. When women's estrogen levels are increased through regular sexual activity, their overall brain activity and memory improves.

\section{Learn Something New}

This could seem obvious, but some people seem to forget it as they age. You can actually capitalize on your brain's ability to learn new things, and make it stronger at the same time! You could have a specific topic during leisure time, but if not, try to learn something like a new word every day. There is a strong correlation between having a working vocabulary and intelligence. 


\section{Write to be Read}

There is great value when you are writing only for your own eyes, but try to imagine what it would be like if someone were to grab your journal and read it now. You should be writing to stimulate your mind, which means writing as if someone else was going to read those pages. The greatest benefit of writing is that it actually expands your brain's capacity. You should always be finding ways to write or read so that you can exercise your mind.

\section{Drugs}

There are good and bad drugs to enhance your brain. Caffeine is a common one used by students in order stay awake and be more alert. Caffeine restricts the blood vessels going to your brain, so it's not clear what the long-term effects might be on the brain. Instead of coffee, try some herbal tea when you need a boost. Both of these have been shown to increase the blood flow to your brain and improve your concentration.

\section{Brain Trust}

If you want to build up your brainpower, then you're going to need others around you who are inspiring and stimulating to you. Read magazines from different fields within your field of study, and make connections with people, places, and things that will give you new opportunities. Use them to help you find solutions to your problems.

\section{Why Critical Thinking Is Important}

As you have just seen, your critical thinking helps you to contribute to a higher cause using the knowledge you have. You can now look at the points that follow, to see how this process helps.

You get to note any arguments that have no basis

You get to note any fallacies contained in the information

You get to introduce objective arguments

You get to strengthen any objective arguments already presented with additional facts

You get a chance to beef up the good arguments with logical arguments

You get a chance to contribute positively to the tasks you find constructive
You get opportunity to improve on existing theories

You get opportunity to improve on the mode of operation in place

You get opportunity to modify the way institutions run, and to enhance their strong points.

\section{Questions you can ask to discipline your thinking}

- What precise question am I trying to answer?

- Is this the best question to ask in this situation?

- Is there a more important question I should be addressing?

- Does this question capture the real issue I am facing?

- Is there a question I should answer before I attempt to answer this question?

- What information do I need to gather to answer the question?

- What conclusions seem justified in light of the facts?

- What is my point of view? Do I need to consider another?

- Is there another way to look at the question?

- What are some related questions need to consider?

- What type of question is this: an economic question, a political question, a legal question, an ethical question, or a complex question with multiple domains?

\section{CONCLUSION}

Your brain is the super-computer that governs your life and body, and it's involved in everything that you do. It is going to determine who you are, what you do, and how well you do it. Therefore, it's imperative that you keep your brain in tip-top condition so that you can make better decisions about your life and think in a logical manner. Thinking logically doesn't mean that you don't have emotions. It means that you are able to come to a conclusion based on rational thinking rather than feelings.

\section{REFERENCE}

1. Buzan, T (1988). Make the most of your Mind of your Mind clegg, London : Pan.

2. Band birch, P(1999) Instant creativity, London : koganpage 
3. COX, G (2001), Ready, aim fire problem- solving, cork: oak tree Press.

4. De Bano, E (1970) Lateral Thinking, Harmondswoth: Penguin,

5. De Bano, E(1971). Lateral Thinking for management, Harmondsworth : Penguin,

6. slone, P(1991). Lateral Thinking Puzzlers, Network : sterling,

7. Wold, J (2001). Do something different, London : virgin book,
8. Simon, B and Nicole, $\mathrm{P}(2016)$. Critical thinking, London : koganpage

9. Johnson, Gerard.(2016)Critical Thinking: Your Ultimate Critical Thinking Guide: Effective Strategies That Will Make You Improve Critical Thinking and Decision Making Skills: London : koganpage.

10. Bradley, Simon; Price, Nicole.(2016) Critical Thinking: Proven Strategies to Improve Decision Making Skills, Increase Intuition and Think Smarter. London : koganpage.

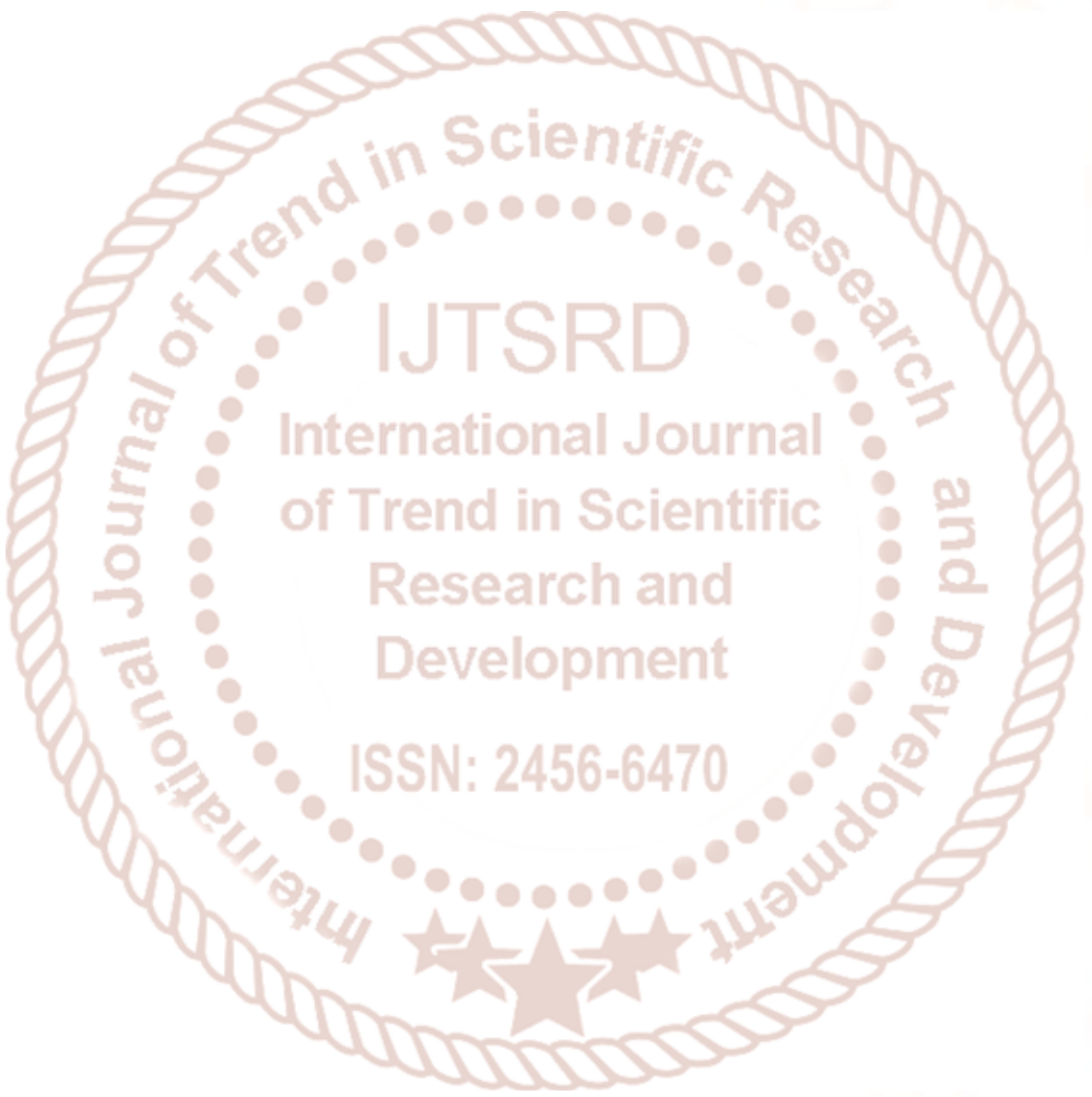

